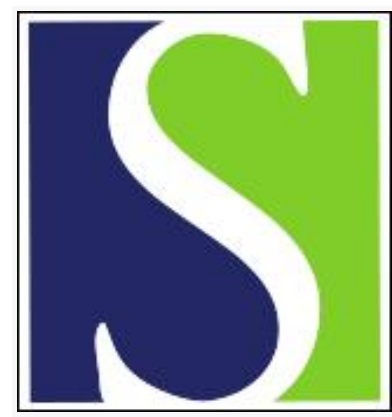

Scand J Work Environ Health 2013;39(5):506-514

https://doi.org/10.5271/sjweh.3352

Published online: 21 Feb 2013, Issue date: 01 Sep 2013

Prognosis of ulnar neuropathy and ulnar neuropathy-like symptoms in relation to occupational biomechanical exposures and lifestyle

by Svendsen SW, Johnsen B, Fuglsang-Frederiksen A, Frost P

Little is known on prognostic factors for ulnar neuropathy confirmed by nerve conduction studies (NCS) and ulnar neuropathy-like symptoms with normal ulnar nerve NCS. Negative prognostic factors included high occupational force requirements, current smoking, obesity, and abnormal NCS. Reduction of high occupational force requirements, smoking, and obesity might improve prognosis of ulnar neuropathy and ulnar neuropathy-like symptoms.

Affiliation: Danish Ramazzini Centre, University Department of Occupational Medicine, Herning Regional Hospital, Gl. Landevej 61, DK-7400 Herning, Denmark. susasven@rm.dk

Refers to the following text of the Journal: 2001;27 suppl 1:1-102

Key terms: biomechanical exposure; body mass index; epidemiology; force; job exposure matrix; lifestyle; musculoskeletal disorder; nerve conduction study; posture; prediction model; prognosis; prognostic factor; repetitive work; smoking; ulnar neuropathy; ulnar neuropathy-like symptom; upper extremity

This article in PubMed: www.ncbi.nlm.nih.gov/pubmed/23429966 


\title{
Prognosis of ulnar neuropathy and ulnar neuropathy-like symptoms in relation to occupational biomechanical exposures and lifestyle
}

\author{
by Susanne Wulff Svendsen, PhD, ${ }^{1}$ Birger Johnsen, PhD, ${ }^{2}$ Anders Fuglsang-Frederiksen, DMedSc, ${ }^{2}$ Poul \\ Frost, $\mathrm{PhD}^{3}$
}

\begin{abstract}
Svendsen SW, Johnsen B, Fuglsang-Frederiksen A, Frost P. Prognosis of ulnar neuropathy and ulnar neuropathylike symptoms in relation to occupational biomechanical exposures and lifestyle. Scand J Work Environ Health. 2013;39(5):506-514. doi:10.5271/sjweh.3352
\end{abstract}

Objective The aim of this paper was to identify prognostic factors for severity of symptoms and disability among patients with ulnar neuropathy confirmed by nerve conduction studies (NCS) or ulnar neuropathy-like symptoms with normal ulnar nerve NCS.

Methods We conducted a cohort study based on a matched case-referent study. In 2008, we mailed a questionnaire to 1179 patients who were examined by NCS for suspected ulnar neuropathy at the age of $\geq 18-<65$ years, 2001-2007. Potential prognostic factors included occupational biomechanical exposures, lifestyle factors, and NCS result. Outcomes were severity of symptoms and disability according to questionnaire scores. Referents delivered reference values. We used ordinal logistic regression.

Results The proportion who responded was $61 \%$, comprising 324 patients with ulnar neuropathy and 396 with ulnar neuropathy-like symptoms. At follow-up, both patient groups had more severe symptoms and disability than age- and sex-matched referents. Abnormal NCS indicated a poorer prognosis regarding symptom severity [odds ratio (OR) $1.44,95 \%$ confidence interval $(95 \% \mathrm{CI}) 1.01-2.01$ ], but not disability $(\mathrm{OR} 0.78,95 \% \mathrm{CI}$ $0.57-1.08)$. High occupational force requirements indicated a poorer prognosis regarding both symptom severity (OR 1.78, 95\% CI 1.10-2.88) and disability (OR 1.66, 95\% CI 1.06-2.59). Other negative prognostic factors for both outcomes were current smoking, obesity, distal upper-extremity fractures, female sex, and a recent NCS date (suggesting improvement over time).

Conclusions NCS confirmation of ulnar neuropathy identified patients with a poorer prognosis regarding symptoms. A negative impact of high occupational force requirements, current smoking, and obesity on both outcomes suggested that reduction of these factors might improve prognosis of ulnar neuropathy and ulnar neuropathy-like symptoms.

Key terms body mass index; epidemiology; force; job exposure matrix; musculoskeletal disorder; nerve conduction study; posture; prognostic factor; prediction model; repetitive work; smoking; upper extremity.

Ulnar neuropathy at the elbow is the second most common entrapment neuropathy following carpal tunnel syndrome (CTS) (1) with a prevalence of $0.6-0.8 \%$ (2) and incidence rates of 20-25 per 100000 person-years $(3,4)$. Diagnosis may be based on history and physical examination, but increasingly, confirmatory nerve conductions studies (NCS) are considered necessary (1). On the other hand, the prognostic value of differentiating between ulnar neuropathy confirmed by NCS and ulnar neuropathy-like symptoms with normal NCS has been questioned $(5,6)$, and among patients with ulnar neuropathy confirmed by NCS, it remains unclear if specific NCS findings can predict prognosis (7-9). NCS are not an integral part of case definitions in occupational studies $(10,11)$.

Ulnar neuropathy may resolve spontaneously $(7,12)$, but $>50 \%$ of patients who did not have surgery still complained of symptoms one year after confirmative NCS (13). Available evidence is insufficient to determine when surgery should be preferred to non-surgical treatment (1). In mild cases, advice to avoid movements and

1 Danish Ramazzini Centre, University Department of Occupational Medicine, Herning Regional Hospital, Denmark.

2 Department of Neurophysiology, Aarhus Hospital, Aarhus University Hospital, Denmark.

3 Danish Ramazzini Centre, Department of Occupational Medicine, Aarhus Hospital, Aarhus University Hospital, Denmark.

Correspondence to: Susanne Wulff Svendsen, Danish Ramazzini Centre, University Department of Occupational Medicine, Herning Regional Hospital, Gl. Landevej 61, DK-7400 Herning, Denmark. [E-mail: susasven@rm.dk] 
positions that provoke symptoms seems to be of prognostic benefit (1). As opposed to this, the Washington State Department of Labor and Industries recently recommended that patients with ulnar neuropathy continue to work until surgery (www.lni.wa.gov/ClaimsIns/ Files/OMD/MedTreat/UlnarNerve.pdf). Thus, there is a need for improved treatment strategies, including a need for evidence-based guidelines on modifications of occupational biomechanical exposures. Prognostic studies may be a first step to achieve this goal.

Few epidemiological studies have examined prognostic factors for ulnar neuropathy $(5,14,15)$. Apart from one study of surgical outcomes in relation to smoking and obesity (5), we are not aware of studies of prognosis in relation to occupational biomechanical exposures and lifestyle factors. We have recently identified high occupational force requirements (16) and smoking (17) as risk factors for ulnar neuropathy confirmed by NCS, and repetitive hand-arm movements (16) and obesity (17) as risk factors for ulnar neuropathy-like symptoms with normal NCS. The same factors may be associated with prognosis. A model that efficiently predicts an individual's probability of a specific outcome may provide insight into potential causal relationships. If the model contains factors that are amenable to interventions, further research could determine if changes of these factors improve prognosis. The model could then serve as a basis for the patients' informed choice regarding modification of work and lifestyle factors.

A recent Cochrane review of treatment for ulnar neuropathy at the elbow recommended the Disability of the Arm, Shoulder and Hand questionnaire (DASH) and the Ulnar Neuropathy at the Elbow Questionnaire (UNEQ) for outcome assessment (1). DASH (18-20) is widely used in studies of upper-extremity musculoskeletal disorders, but has rarely been used in studies of peripheral nerve affection $(15,21-23)$. The validity of DASH for assessing disability related to ulnar neuropathy at the elbow has recently been corroborated by results showing that scores reflected clinical staging (23). UNEQ is a disease specific questionnaire designed to assess severity of symptoms related to ulnar neuropathy at the elbow (24).

The aim of this study was to identify prognostic factors for severity of symptoms (UNEQ) and disability (DASH) among patients referred for NCS for suspected ulnar neuropathy and to construct a prediction model for each outcome. As potential prognostic factors, we focused on occupational biomechanical exposures, lifestyle factors, and NCS result. If NCS result could be identified as a prognostic factor, this would support the prognostic validity of NCS among patients suspected of ulnar neuropathy and, at the same time, corroborate our overall hypothesis that ulnar neuropathy differs from ulnar neuropathy-like symptoms, not only with respect to profile of risk factors $(16,17)$, but also with respect to prognosis. Based on our previous findings (16), we specifically hypothesized that high force requirements would be a prognostic factor.

\section{Methods}

\section{Study population}

We conducted a cohort study based on a matched casereferent study. The study population has been described previously (16). In brief, we used data from the Danish National Patient Register (25) to identify all contacts to the Department of Neurophysiology, Aarhus University Hospital, 1 March 2001 to 30 June 2007, with a referral diagnosis of mononeuropathy of upper limb [group G56 in the International Classification of Disease, $10^{\text {th }}$ revision (ICD-10)] and a discharge diagnosis of either ulnar neuropathy (ICD-10 code G56.2) or no neuropathy (ICD-10 codes Z). The population was restricted to patients who were $\geq 18-<65$ years old at the date of their first contact and examined by NCS across the elbow; this was done only if a supervising consultant suspected ulnar neuropathy based on referral information, history, and/or signs. Patients were excluded if they had a traumatic lesion or ulnar neuropathy as part of a polyneuropathy. Some of the patients with ulnar neuropathy had CTS as well, and due to registration errors, a number of patients with a Z-diagnosis actually had CTS. We left patients who (also) received a diagnosis of CTS in the study, except in subanalyses. Questionnaire data was collected by mail between 7 January and 30 April 2008, and responding patients constituted the prognostic cohort.

The referents in the original case-referent study (16) delivered background population values for UNEQ and DASH. Three referents per case were randomly sampled in the Danish National Health Service Register (26), individually matched on sex, age ( $+/-2 \frac{1}{2}$ years), and primary health care provider at the NCS date of the case.

The Danish Data Protection Agency authorized the study. The five Danish administrative regions approved the use of data from the Danish National Health Service Register, and the Danish National Board of Health permitted the use of neurophysiological data. In Denmark, register- and questionnaire-based studies require neither approval by biomedical research ethics committees nor written informed consent.

\section{Potential prognostic factors}

NCS was performed with needle or surface electrodes (16). The Department of Neurophysiology used normative values represented by regression equations that corrected for age, height, and/or segment length. Distal latencies, motor and sensory amplitudes, and conduction velocities 
were expressed in Z-scores, ie, standard deviations from the normative values. The $Z$-score for distal latency was considered abnormal if it was $>2$, and Z-scores for motor and sensory amplitude as well as conduction velocity were considered abnormal if they were $<-2$ (27). If at least one Z-score was abnormal or if there was a partial motor conduction block (28), the patient was classified as having ulnar neuropathy, otherwise as having ulnar neuropathylike symptoms. The cut-off values were in accordance with the department's clinical practice.

For each participant, occupational biomechanical exposures in the year before the NCS year were assessed by combining self-reported job titles with quantitative job exposures extracted from a job exposure matrix (JEM) based on five experts' ratings (16). The JEM comprised 169 groups of jobs that were expected to have similar exposure profiles with respect to occupational force requirements (force-score: $0=$ light, $1=$ somewhat hard, 2=hard, 3=very hard, 4=near maximal), repetitive movements of elbow or wrist ( $\geq 4$ movements per minute), non-neutral postures of elbow or wrist, and hand-arm vibration (HAV) with accelerations $\geq 3 \mathrm{~m} / \mathrm{s}^{2}$. The three last-mentioned exposures were rated as hours per day in half-hour intervals.

Questionnaire information was collected on height, weight, smoking status, weekly alcohol consumption, comorbidity (diabetes, thyroid or renal disorders), handedness, fracture of the elbow, forearm or wrist (ever: no/yes), and year of surgery for nerve entrapment at the elbow. Only fractures that occurred on the side examined by NCS were included in the analyses, and only surgical operations that occurred after the NCS examination and on the examined side were included in the analyses (no/yes). Patients who stated that they used both hands equally well were categorized as right-handed. Body mass index (BMI) was calculated as weight / height square $\left(\mathrm{kg} / \mathrm{m}^{2}\right)$. Alcohol consumption was summed up as units per week. We also included age, sex, and NCS year among the studied potential prognostic factors.

We used education level as a marker for socioeconomic status. Based on data from the Danish National Register on Public Transfer Payments (29), we assessed education level as indicated by unemployment insurance fund membership in the year of the NCS. The information was categorized into higher or medium-level education (eg, engineers; managers and executives; Danish health organizations - including nurses), vocational education and training (eg, wood, industry and building workers; restaurant and brewery employees), low education level (eg, general workers; trade and labor), and missing. This marker of socioeconomic status has been identified as a strong predictor of work disability among surgical shoulder patients (30) and patients with a herniated lumbar disc (31). We classified cash benefit together with low education level (cash benefit is part of the lowest level of the social safety net in Denmark). From the same register, we obtained information on permanent transfer incomes at the NCS date and the number of weeks with health-related transfer incomes within 52 weeks following the NCS date (health-related transfer incomes were sickness benefit, flex-job, and disability pension; a flex-job is a subsidized job type for persons whose work capacity has been permanently reduced for health-related reasons; disability pension is a healthrelated benefit for persons who are permanently unable to work even in a flex-job).

\section{Outcome measures}

The original UNEQ contains nine questions on numbness or tingling in the fourth and fifth fingers, elbow pain, change of symptoms in relation to elbow position, and impaired dexterity (24). UNEQ is side-specific. In our questionnaire, we shunted respondents around questions concerning severity of pain and pain in relation to elbow position if they had not experienced elbow pain within the past four weeks. Likewise, we shunted respondents around more specific questions regarding numbness or tingling if they had not experienced numbness or tingling in the hand within the past four weeks. Respondents received the lowest score for items that they were shunted around. Furthermore, we asked about severity of symptoms in relation to elbow positions instead of asking about change in symptoms. In order to limit the number of different time windows in our questionnaire, we asked about the preceding four weeks, whereas the original UNEQ concerns the preceding two weeks. Finally, each item had seven possible answers in our questionnaire (inspired by the Pain Module of the Standard Evaluation Questionnaire) (32) with "no pain" (or "no numbness or tingling") and "intolerable pain" (or "intolerable numbness or tingling") as minimal and maximal anchors. We rescaled the answers to a score ranging from 1-5 in accordance with the original UNEQ. We then calculated the final score as the mean score of the nine items, a high score indicating severe symptoms. A missing response to $\leq 1$ of the items 2,3 , and 4 and $\leq 1$ of the items 6,7 , and 8 was replaced by the mean value of the responses to the two other questions. The score was not calculated if $\geq 2$ responses were missing in each of these groups of questions or in case of any missing responses to items 1, 5, and 9. The authors translated UNEQ using the published English and Italian versions, assuming that question 7 concerned pain in the elbow as in the Italian version and not pain in the last two fingers as in the English version (24). Patients with bilateral ulnar neuropathy arbitrarily received the UNEQ score for the left side.

The DASH is a 30 -item questionnaire that measures disability of both upper extremities simultaneously. It is divided into six domains: daily activities, symptoms, 
social function, work function, sleep, and confidence $(18-20)$. We respected the original time window of DASH, ie, the past week. In our questionnaire, we shunted respondents who did not report pain or discomfort in shoulders, arms, or hands within the past week around the DASH and they received the lowest DASH score. We omitted item 21 concerning sexual activities, which we thought was not socially acceptable in the context of our mailed questionnaire $(33,34)$. The score was scaled from $0-100$ with greater disability reflected by a higher score. We did not calculate DASH scores if $>3$ responses were missing. When we designed our questionnaire, the authorized Danish version of DASH was not yet available, so we translated DASH ourselves - our translation was very close to the authorized version.

\section{Statistical analysis}

We calculated descriptive statistics for UNEQ and DASH scores. Mean scores for patients with ulnar neuropathy and those with ulnar neuropathy-like symptoms were compared by Wilcoxon rank sum test. The distribution of DASH scores was skewed towards lower values, so we classified DASH scores in four categories of approximately equal size for further analyses; the DASH categories were $0,>0-20,>20-40,>40-100$.

We applied ordered logistic regression to investigate potential prognostic factors for the outcomes. Odds ratios (OR) were estimated for one potential prognostic factor at a time in basic models including NCS year (dichotomized: 2001- $\leq 2003,2004-\leq 2007$ ), sex, and continuous age. We also estimated OR in full models including all potential prognostic factors under study except education level, which we, a priori, decided not to include in the main analyses due to expected correlations with other potential prognostic factors. To explore any decline in symptoms with time since NCS, we performed alternative full model analyses including NCS year (trichotomized: 2001-2002, 2003-2004, 2005-2007). We also repeated the full model analyses (i) with CTS (no/yes) as an additional potential prognostic factor and (ii) restricted to patients without CTS. To establish prediction models for a specific UNEQ score (rounded to whole numbers 1-5) and a specific DASH category, we performed manual backward elimination (35) with use of a P-value of $\geq 0.1$, and subsequent refitting of the model. We used STATA 11.2 (StataCorp LP, College Station, TX, USA).

If information on occupational exposures was missing, patients were excluded from the analyses. Thus, the analyses were based on patients who had a job in the year before the NCS. Patients with missing information on education level were placed in the group with vocational education and training, and patients with missing information on BMI received the mean of nonmissing values for the entire study population including referents. We classified patients with missing information on handedness as right-handed in order to decide if the dominant or non-dominant side was affected. In case of missing smoking status, we classified patients as ex-smokers. Patients with missing information on other potential prognostic factors received the reference levels. We repeated the full-model analyses excluding participants with missing values.

\section{Results}

We mailed our questionnaire to 546 patients with ulnar neuropathy, $324(59.3 \%)$ of whom responded, and to 633 patients with ulnar neuropathy-like symptoms, 396 $(62.6 \%)$ of whom responded. The proportion of the referents who responded was $57.5 \%$. As reported previously (16), persons with low education level and persons on cash benefit were slightly underrepresented among respondents. The percentage, who received permanent transfer incomes at the NCS date, was $18.2 \%$ among respondents, and $19.4 \%$ among non-respondents. On average, respondents, who did not receive permanent transfer incomes at the NCS date, received healthrelated transfer incomes for 9.6 weeks within 52 weeks following the NCS date as compared to 11.9 weeks for non-respondents. The median follow-up time was 4 (1-7) years.

Patients with ulnar neuropathy had a mean UNEQ score of 2.12 [standard deviation (SD) 1.10], which was significantly larger than the mean UNEQ score of 1.88 (SD 0.96) for patients with ulnar neuropathy-like symptoms $(\mathrm{P}=0.01)$. The mean DASH scores of 22.5 (SD 23.8) and 23.9 (SD 22.5), respectively, did not differ $(\mathrm{P}=0.19)$. Both patient groups had clearly elevated scores when compared to their matched population referents, who had mean UNEQ scores of 1.15 (SD 0.44) and 1.20 (SD 0.51), and mean DASH scores of 9.1 (SD 15.0) and 11.0 (SD 18.0).

Table 1 displays characteristics of the study population (patients with ulnar neuropathy and ulnar neuropathy-like symptoms) according to occupational force requirements. A relatively high proportion of men and a relatively young age characterized the group with a high force-score $(\geq 1)$. The proportion of current smokers and the proportion with low education level increased with increasing force-score. A high force-score tended to coincide with high values for repetition time (correlation coefficient 0.76), non-neutral-posture time (correlation coefficient 0.66 ), and HAV time (correlation coefficient 0.44 ). The most frequent jobs with a high forcescore were carpenters, smiths, lorry drivers, machinists, farmers, and car mechanics among men, and nursing aids, cleaners, physiotherapists, kitchen assistants, and 
Table 1. Distribution of study population according to biomedical, personal, lifestyle, and occupational factors within categories of occupational force requirements.

\begin{tabular}{|c|c|c|c|c|}
\hline & \multicolumn{4}{|c|}{ Force-score } \\
\hline & $\begin{array}{c}\text { Missing } \\
\mathrm{N}=81\end{array}$ & $\begin{array}{c}0 \\
\mathrm{~N}=176\end{array}$ & $\begin{array}{l}>0-<1 \\
N=165\end{array}$ & $\begin{array}{c}\geq 1 \\
\mathrm{~N}=298\end{array}$ \\
\hline & $\%$ & $\%$ & $\%$ & $\%$ \\
\hline \multicolumn{5}{|l|}{ Condition } \\
\hline Ulnar neuropathy & 54.3 & 39.2 & 41.8 & 47.7 \\
\hline Ulnar neuropathy-like symptoms & 45.7 & 60.8 & 58.2 & 52.3 \\
\hline \multicolumn{5}{|l|}{ Comorbidity a } \\
\hline No & 76.5 & 85.2 & 89.7 & 88.6 \\
\hline Yes & 23.5 & 14.8 & 10.3 & 11.4 \\
\hline \multicolumn{5}{|l|}{ Fracture, ipsilateral } \\
\hline No & 79.0 & 79.0 & 80.6 & 78.5 \\
\hline Yes & 21.0 & 21.0 & 19.4 & 21.5 \\
\hline \multicolumn{5}{|l|}{ Dominant-sided condition } \\
\hline No & 54.3 & 52.8 & 53.9 & 52.7 \\
\hline Yes & 45.7 & 47.2 & 46.1 & 47.3 \\
\hline \multicolumn{5}{|l|}{ Surgery, ipsilateral elbow } \\
\hline No & 81.5 & 88.1 & 87.3 & 83.9 \\
\hline Yes & 18.5 & 11.9 & 12.7 & 16.1 \\
\hline \multicolumn{5}{|l|}{ Sex } \\
\hline Male & 40.7 & 47.7 & 32.1 & 55.4 \\
\hline Female & 59.3 & 52.3 & 67.9 & 44.6 \\
\hline \multicolumn{5}{|l|}{ Nerve conduction studies (year) } \\
\hline $2001-\leq 2003$ & 48.2 & 42.1 & 42.4 & 39.6 \\
\hline $2004-\leq 2007$ & 51.9 & 58.0 & 57.6 & 60.4 \\
\hline \multicolumn{5}{|l|}{ Age at follow-up (years) } \\
\hline$\leq 45$ & 25.9 & 29.6 & 37.0 & 38.6 \\
\hline$>45-\leq 55$ & 24.7 & 28.4 & 30.3 & 28.2 \\
\hline$>55$ & 49.4 & 42.1 & 32.7 & 33.2 \\
\hline \multicolumn{5}{|l|}{ Body mass index } \\
\hline$<20 \mathrm{~kg} / \mathrm{m}^{2}$ & 2.5 & 3.4 & 8.5 & 4.4 \\
\hline$\geq 20-<25 \mathrm{~kg} / \mathrm{m}^{2}$ & 30.9 & 38.6 & 37.0 & 32.9 \\
\hline$\geq 25-<30 \mathrm{~kg} / \mathrm{m}^{2}$ & 32.1 & 37.5 & 38.2 & 37.6 \\
\hline$\geq 30 \mathrm{~kg} / \mathrm{m}^{2}$ & 28.4 & 18.2 & 15.2 & 21.5 \\
\hline Missing & 6.2 & 2.3 & 1.2 & 3.7 \\
\hline \multicolumn{5}{|l|}{ Smoking status } \\
\hline Never smoker & 37.0 & 39.8 & 32.7 & 29.5 \\
\hline Ex-smoker & 14.8 & 27.3 & 27.9 & 18.8 \\
\hline Current smoker & 40.7 & 31.8 & 37.6 & 46.0 \\
\hline Missing & 7.4 & 1.1 & 1.8 & 5.7 \\
\hline \multicolumn{5}{|l|}{ Alcohol (units /week) } \\
\hline$\leq 1$ & 44.4 & 21.0 & 28.5 & 28.9 \\
\hline$>1-<7$ & 18.5 & 34.7 & 41.8 & 32.6 \\
\hline$\geq 7$ & 22.2 & 38.6 & 23.0 & 32.9 \\
\hline Missing & 14.8 & 5.7 & 6.7 & 5.7 \\
\hline \multicolumn{5}{|l|}{ Education level } \\
\hline Higher or medium-level & 9.9 & 31.8 & 30.9 & 7.7 \\
\hline Vocational & 22.2 & 46.0 & 25.5 & 38.6 \\
\hline Low (including cash benefit) & 55.6 & 9.1 & 39.4 & 51.7 \\
\hline Missing & 12.3 & 13.1 & 4.2 & 2.0 \\
\hline \multicolumn{5}{|l|}{ Repetition time } \\
\hline 0 hours/day & - & 96.0 & 45.5 & 28.9 \\
\hline$>0-<2.5$ hours/day & - & 4.0 & 37.6 & 14.4 \\
\hline$\geq 2.5$ hours/day & - & 0.0 & 17.0 & 56.7 \\
\hline Missing & 100.0 & - & - & - \\
\hline \multicolumn{5}{|l|}{ Non-neutral-posture time } \\
\hline$<1$ hour/day & - & 63.6 & 59.4 & 28.9 \\
\hline$\geq 1-<2$ hours/day & - & 11.9 & 35.8 & 14.4 \\
\hline$\geq 2$ hours/day & - & 24.4 & 4.9 & 56.7 \\
\hline Missing & 100.0 & - & - & - \\
\hline Hand-arm-vibration time ${ }^{b}$ & & & & \\
\hline 0 hours/day & - & 100.0 & 100.0 & 70.5 \\
\hline$>0-<1$ hour/day & - & 0.0 & 0.0 & 14.1 \\
\hline$\geq 1$ hour/day & - & 0.0 & 0.0 & 15.4 \\
\hline Missing & 100.0 & - & - & - \\
\hline
\end{tabular}

a Diabetes, thyroid or renal disorders.

${ }^{b}$ Time with exposure to hand-arm vibration with accelerations $\geq 3 \mathrm{~m} / \mathrm{s}^{2}$. slaughterhouse workers among women. These jobs accounted for $30 \%$ of high force-scores among men and $60 \%$ among women. Frequent jobs with a medium forcescore $(>0-<1)$ were nursery and kindergarten teachers and manufacturing workers for either sex, nursery and kindergarten assistants and nurses for women, and taxi and coach drivers and stock clerks for men.

The percentage with CTS was 5.3\% (17/324) among patients with ulnar neuropathy and $8.3 \%(33 / 396)$ among patients with ulnar neuropathy-like symptoms. Across categories of occupational force requirements, the percentage with CTS was $6.8 \%$ (force-score $=0$ ), $5.5 \%$ (force-score $>0-<1$ ), $8.1 \%$ (force-score $\geq 1$ ), and $6.2 \%$ (missing force-score). Among patients with ulnar neuropathy and ulnar neuropathy-like symptoms, respectively, $60.5 \%$ and $51.7 \%$ still had symptoms (rounded UNEQ score $>1$ ) at follow-up, and $44.5 \%$ and $49.4 \%$ still had disability (DASH score $>20$ ); $30.3 \%$ and $1.8 \%$ had undergone surgery for nerve entrapment at the elbow. Among patients with ulnar neuropathy, $55 \%$ of the surgically treated patients and $49 \%$ of the remainder had a force-score $\geq 1$.

Table 2 shows the main results on the prognosis of patients referred for NCS for suspected ulnar neuropathy. Across the models (basic, full, and prediction models), NCS result (abnormal/normal) was a prognostic factor regarding UNEQ, but not DASH. For both UNEQ and $\mathrm{DASH}$, a force-score $\geq 1$, current smoking, and BMI $\geq 30 \mathrm{~kg} / \mathrm{m}^{2}$ predicted a less favorable prognosis. A more recent NCS year was associated with higher UNEQ and DASH scores, suggesting a tendency for improvement over time. When we applied the trichotomized NCS year variable with 2001-2002 as the reference, the OR for 2003-2004 was 1.51 (95\% CI 1.00-2.28) and the OR for 2005-2007 was 1.51 (95\% CI 1.01-2.26) for UNEQ, suggesting that improvement in symptoms took place within the first couple of years after NCS. The corresponding OR for DASH were 1.44 (95\% CI $0.97-2.12$ ) and 1.69 (95\% CI 1.17-2.44), suggesting a gradual improvement over time. Other OR in the models did not change. Introduction of education level into the full models did not alter the overall findings (results not shown). When we repeated the full model analyses with CTS (no/yes) as an additional potential prognostic factor, the results regarding UNEQ and DASH did not change (results not shown). After restriction to patients without CTS and patients without missing covariates, results were similar to those presented in table 2 (results not shown). We did not include surgery in the full models since almost only patients with ulnar neuropathy had surgery. In basic models, surgery for nerve entrapment at the elbow indicated an unfavorable prognosis with respect to UNEQ [OR 1.90 (95\% CI 1.24-2.93)], but not DASH [OR 1.11 (95\% CI 0.74-1.68)] (results regarding surgery do not appear in the table). 
Table 2. Ordered logistic regression models for prognosis of patients referred for nerve conduction studies (NCS) on suspicion of ulnar neuropathy as regards symptom severity and disability. Use of the prediction model is explained in the text, see cuts below the table. ${ }^{\text {a }}$ Significant results are displayed in bold. [DASH=Disability of the Arm, Shoulder, and Hand; HAV=hand-arm vibration; NA=not applicable; OR=odds ratio; UNEQ=Ulnar Neuropathy at the Elbow Questionnaire; 95\% Cl=95\% confidence interval].

\begin{tabular}{|c|c|c|c|c|c|c|c|c|c|c|c|c|c|c|}
\hline & \multicolumn{7}{|c|}{ Symptom severity (UNEQ, affected side) } & \multicolumn{7}{|c|}{ Disability (DASH ${ }^{\mathrm{b}}$, both sides together) } \\
\hline & \multirow{2}{*}{$\begin{array}{c}\begin{array}{c}\text { Basic } \\
\text { model }\end{array} \\
\mathrm{OR}\end{array}$} & \multicolumn{2}{|c|}{$\begin{array}{c}\text { Full } \\
\text { model d }\end{array}$} & \multicolumn{4}{|c|}{$\begin{array}{l}\text { Prediction } \\
\text { model }\end{array}$} & \multirow{2}{*}{$\begin{array}{c}\begin{array}{c}\text { Basic } \\
\text { model }\end{array} \\
\text { OR }\end{array}$} & \multicolumn{2}{|c|}{$\begin{array}{c}\text { Full } \\
\text { model d }\end{array}$} & \multicolumn{4}{|c|}{$\begin{array}{l}\text { Prediction } \\
\text { model }\end{array}$} \\
\hline & & $\mathrm{OR}$ & $95 \% \mathrm{Cl}$ & $\beta$ & SE & $\mathrm{OR}$ & $95 \% \mathrm{Cl}$ & & $\mathrm{OR}$ & $95 \% \mathrm{Cl}$ & $\beta$ & SE & $\mathrm{OR}$ & $95 \% \mathrm{Cl}$ \\
\hline Male & NA & 1.00 & & & & 1.00 & & NA & 1.00 & & & & 1.00 & \\
\hline $\begin{array}{l}\text { Female } \\
\text { NCS year }\end{array}$ & NA & 1.49 & $1.02-2.19$ & 0.50 & 0.18 & 1.64 & $1.16-2.32$ & NA & 2.42 & $1.66-3.53$ & 0.99 & 0.16 & 2.69 & 1.97 \\
\hline $2001-\leq 2003$ & NA & 1.00 & & & & 1.00 & & NA & 1.00 & & & & 1.00 & \\
\hline $2004-\leq 2007$ & NA & 1.48 & $1.07-2.04$ & 0.38 & 0.16 & 1.46 & $1.06-2.01$ & NA & 1.49 & $1.10-2.01$ & 0.37 & 0.15 & 1.45 & 1.07-1.95 \\
\hline $\begin{array}{l}\text { Ulnar neuropathy-like } \\
\text { symptoms }\end{array}$ & 1.00 & 1.00 & & & & 1.00 & & 1.00 & 1.00 & & & & & \\
\hline $\begin{array}{l}\text { Ulnar neuropathy } \\
\text { Fracture, ipsilateral }\end{array}$ & 1.74 & 1.42 & $1.01-2.01$ & 0.35 & 0.17 & 1.42 & $1.02-1.98$ & B 1.05 & 0.78 & $0.57-1.08$ & Not incl & luded & & ot included \\
\hline No & 1.00 & 1.00 & & & & 1.0 & & 1.00 & 1.00 & & & & 1.00 & \\
\hline Yes & 1.56 & 1.47 & $1.01-2.15$ & 0.40 & 0.19 & 1. & $1.03-2.16$ & $6 \quad 1.58$ & 1.58 & $1.10-2.27$ & 0.45 & 0.18 & 1.57 & $1.10-2.24$ \\
\hline Never smoker & 1.00 & 1.00 & & & & 1.00 & & 1.00 & 1.00 & & & & 1.00 & \\
\hline Ex-SI & 1.00 & 1.00 & $0.66-1.52$ & -0.01 & 0.21 & 0.99 & 0.6 & $9 \quad 1.22$ & 1.23 & & 0.19 & 0.19 & 1.21 & 0.8 \\
\hline $\begin{array}{l}\text { Current smoker } \\
\text { Body mass index }\end{array}$ & 1.61 & 1.49 & $1.02-2.19$ & 0.38 & 0.19 & 1.47 & $1.01-2.12$ & 21.64 & 1.54 & $1.08-2.21$ & 0.40 & 0.18 & 1.49 & $1.06-2.11$ \\
\hline $\begin{array}{l}<20 \mathrm{~kg} / \mathrm{m}^{2} \\
>20-<25 \mathrm{~kg} / \mathrm{m}\end{array}$ & $\begin{array}{l}1.50 \\
1.00\end{array}$ & $\begin{array}{l}1.42 \\
1.00\end{array}$ & $0.70-2.86$ & 0.34 & 0.36 & $\begin{array}{l}1.40 \\
1.00\end{array}$ & $0.70-2.81$ & $\begin{array}{l}1.65 \\
1.00\end{array}$ & $\begin{array}{l}1.84 \\
1.00\end{array}$ & $0.94-3.60$ & 0.53 & 0.34 & $\begin{array}{l}1.71 \\
1.00\end{array}$ & $0.88-3.32$ \\
\hline$\geq 25-<30 \mathrm{~kg} / \mathrm{m}^{2}$ & 1.40 & 1.44 & $1.00-2.08$ & 0.35 & 0.18 & 1.42 & 0.9 & $4 \quad 1.06$ & 1.09 & & 0.06 & 0.17 & 1.06 & 0.7 \\
\hline$\geq 30 \mathrm{~kg} / \mathrm{m}^{2}$ & 1.76 & 1.76 & $1.12-2.74$ & 0.56 & 0.22 & 1.76 & $1.14-2.71$ & 11.74 & 1.64 & $1.07-2.51$ & 0.57 & 0.21 & 1.76 & $1.16-2.67$ \\
\hline Force-score & & & & & & & & & & & & & & \\
\hline 0 & 1.00 & 1.00 & & & & $1 .($ & & 1.00 & 1.00 & & & & 1.00 & \\
\hline$>0$ & 1.29 & 1.37 & $0.83-2.24$ & 0.24 & 0.22 & 1.2 & $0.83-1.94$ & $4 \quad 0.91$ & 0.93 & $0.58-1.48$ & -0.12 & 0.20 & 0.89 & $0.59-1.32$ \\
\hline$\geq 1$ & 1.96 & 1.78 & $1.10-2.88$ & 0.57 & 0.19 & 1.78 & $1.22-2.58$ & B 1.75 & 1.66 & $1.06-2.59$ & 0.51 & & 1.66 & $1.17-2.36$ \\
\hline
\end{tabular}

a UNEQ: Cut1 1.27 (95\% Cl 0.73-1.80); cut2 2.57 (95\% Cl 2.00-3.14); cut3 3.73 (95\% Cl 3.11-4.34); cut4 6.18 (95\% Cl 5.20-7.16). DASH: Cut1 1.22 (95\% Cl 0.38-2.07); cut2 2.42 (95\% Cl 1.56-3.28); cut3 $3.63(95 \% \mathrm{Cl} 2.74-4.52)$

${ }^{\circ}$ DASH scores were divided into four categories: $0,>0-\leq 20,>20-\leq 40,>40-\leq 100$.

c Basic models included sex, age, and NCS year for one potential prognostic factor at a time.

d Full models included all variables in the table and age, comorbidity (diabetes, thyroid or renal disorders; no/yes), dominant-sided condition (no/yes), repetition time $(0,>0-<2.5, \geq 2.5$ hours/day), non-neutral-posture time $(<1, \geq 1-<2, \geq 2$ hours/day), HAV time $(0,>0-<1, \geq 1$ hour/day), and alcohol (units /week; $\leq 1,>1-<7, \geq 7)$.

As an example of how to use the prediction models presented in table 2 to calculate the probability of a specific outcome, the probability (Pr) of a UNEQ score $\geq 3$ can be calculated by the equation:

$\operatorname{Pr}(\mathrm{UNEQ} \geq 3)=1-\operatorname{Pr}(\mathrm{UNEQ}<3)=$

$1-1 /(1+\exp (0.50 \times$ female sex $+0.35 \times$ ulnar neuropathy $+0.38 \times$ recent NCS year $+0.40 \times$ fracture $-0.01 \times$ ex-smoker $+0.38 \times$ current smoker + $0.34 \times \mathrm{BMI}<20 \mathrm{~kg} / \mathrm{m}^{2}+0.35 \times \mathrm{BMI} \geq 25-<30 \mathrm{~kg} / \mathrm{m}^{2}$ $+0.56 \times \mathrm{BMI} \geq 30 \mathrm{~kg} / \mathrm{m}^{2}+0.24 \times$ force-score $>0-<1$ $+0.57 \times$ force-score $\geq 1$ - cut 2 )), where all variables are coded 0 for no and 1 for yes. (The probability of getting a UNEQ score of 1 or 2 is subtracted using cut $2=2.57$ ).

Consider a patient who has symptoms and signs consistent with ulnar neuropathy, and who is characterized by female sex, ulnar neuropathy, current smoking, obesity $\left(\geq 30 \mathrm{~kg} / \mathrm{m}^{2}\right.$ ), a high force-score, and reference levels of other variables in the prediction model. Her probability of becoming free from symptoms (receiving a rounded
$\mathrm{UNEQ}=1$, ie, cut 1 must be used $)$ would be $25 \%[1 /(1+$ $\exp (0.50+0.35+0.38+0.56+0.57-1.27)) \times 100 \%]$ as compared to $61 \%[1 /(1+\exp (0.50+0.35-0.01-1.27))$ $\times 100 \%]$ if she had instead been an ex-smoker with a normal BMI $\left(\geq 20-<25 \mathrm{~kg} / \mathrm{m}^{2}\right)$ and a force-score of 0 .

\section{Discussion}

Among patients with ulnar neuropathy and ulnar neuropathy-like symptoms, respectively, $60.5 \%$ and $51.7 \%$ still had symptoms and $44.5 \%$ and $49.4 \%$ still had disability after a median follow-up time of 4 years. Both patient groups had more severe symptoms and disability than age- and sex-matched referents. We identified female sex, current smoking, BMI $\geq 30 \mathrm{~kg} / \mathrm{m}^{2}$, distal upper-extremity fracture, and high occupational force requirements as negative prognostic factors with regard to symptom severity and disability. There was a tendency for improvement over time. An abnormal NCS result confirming ulnar 
neuropathy indicated an unfavorable prognosis with respect to symptoms of ulnar neuropathy, but not disability, and surgery for nerve entrapment at the elbow showed the same prognostic pattern. We constructed prediction models for both symptom severity and disability.

All patients were clinically suspected of ulnar neuropathy by the supervising consultant according to the examination strategy of the neurophysiological department. Thus, we consider it unlikely that co-occurrence of other disorders such as proximal nerve compression affected our results noticeably, even though such disorders might occur more often in the group with ulnar neuropathy-like symptoms. A standardized clinical examination protocol was not used for data registration at the NCS date (baseline), although this would have been preferable. Due to the retrospective data collection, we also did not have baseline UNEQ and DASH scores. This meant that we were unable to judge if high baseline scores characterized patients who subsequently underwent surgery for nerve entrapment at the elbow, but this may well have been the case. High baseline scores could then be part of the explanation why the surgery patients had relatively high UNEQ scores at follow-up. Alternatively, the finding might reflect complications of the surgical treatment per se, but little is known about the occurrence of adverse events (1).

We analyzed patients with ulnar neuropathy and ulnar neuropathy-like symptoms together because we did not want to assume beforehand that the NCS result was a prognostic factor. Due to a limited number of patients, we did not proceed to stratify the model by condition. This will be relevant in future prognostic studies.

We assessed occupational exposures based on the job held in the year before the NCS year (these exposures were highly correlated with exposures estimated for a five-year period before the NCS year) (16), whereas we did not collect exposure information for the follow-up period. If the prognostic effects were solely related to exposures before the NCS date, this would imply that later modifications of occupational force requirements would be useless. This interpretation of the results corresponds to assuming that all patients reduced their force-scores to 0 after the NCS examination, which seems unlikely. Thus, our results probably best reflected prognostic effects of continuous and unchanged occupational biomechanical exposures, but underestimated these effects to the extent that patients reduced their exposures. We may also have underestimated the impact of high occupational force requirements due to over-adjustment because we included posture, repetitive movements, and HAV in our full models.

Patients with symptoms may tend to overestimate their occupational exposures, which could lead to overestimated associations between high exposure levels and poor outcomes in retrospective studies relying on self-reported exposures. The present study had the advantage that we assessed occupational biomechanical exposures by means of a JEM based on expert ratings, ie, independently of the symptom status of the patients. The study population represented a variety of occupational biomechanical exposures and a wide range of exposure levels and daily exposure durations. Thus, with the exception of HAV that occurred infrequently, exposure contrasts were present as a prerequisite for the ability of our study to assess the exposures as prognostic factors. This was also true of the studied lifestyle factors, except that high levels of alcohol consumption were hardly represented so that we could not assess the potential prognostic effects of alcoholism.

We were able to compare respondents and nonrespondents with respect to a number of baseline characteristics. There was a small tendency that non-respondents had lower education level, which was presumably associated with higher occupational exposures, and the first year after NCS they received more health-related transfer incomes than respondents. Thus, we may have underestimated symptoms and disability at follow-up due to non-response, but overall, respondents and nonrespondents were much alike.

When we planned our study, UNEQ had only been used in the study that introduced the questionnaire (24). Surprisingly, UNEQ has still to come into common use. We carefully translated UNEQ into Danish, but we did not follow formal procedures of forward and backward translation, and we used a slightly modified version of the questionnaire. Instead, our study benefitted from the possibility of internal comparisons between patients with ulnar neuropathy, patients with neuropathy-like symptoms, and background population scores. A further advantage was the possibility of comparing UNEQ and DASH scores.

Among patients with ulnar neuropathy, we found a mean UNEQ score of 2.12 (SD 1.10), which was close to the mean score of 2.03 (SD 0.7 ) originally reported for Italian patients with ulnar neuropathy (24). To our knowledge, a minimal clinically important change has not been reported for UNEQ, but a change in mean UNEQ scores from 2.03 to 1.73 was originally found to correlate significantly with a score for patient satisfaction (24). Thus, it seems likely that achievable changes would be of clinical importance, assuming that positive changes of the factors in the prediction model would actually improve prognosis. The fact that the NCS result (abnormal/normal) was a prognostic factor with respect to UNEQ, but not DASH scores, corroborated the specificity of UNEQ with respect to symptoms related to the ulnar nerve.

The observed mean DASH score for the background population was close to reported normative values (36). A 10-point difference in mean DASH scores has been reported as a minimal clinically important difference (37), which suggests that both patient groups had clinically importantly elevated DASH scores when compared to their matched population referents. Our results indicated that symptom and disability scores decreased over time, 
and in agreement with this, the observed mean DASH scores of around 23 for both patient groups were lower than preoperative scores of 28 to 33 reported for patients with ulnar neuropathy, but higher than corresponding postoperative values of 7 to $13(21,23)$. The DASH scores were substantially lower than mean DASH scores of 44 (SD 22) reported for patients who were assessed between 6 months and 15 years (median 14 months) after a traumatic upper-extremity nerve injury, including brachial plexus injury in $37 \%$ of the cases (15). Brachial plexus injuries have been found to be associated with mean DASH scores of 55 to 60 (22). A previous study of DASH scores in patients with upper extremity disorders at shoulder or wrist level showed that patients who were working had mean DASH scores of 27, whereas patients who were unable to work had mean DASH scores of 51 (18). Thus, on average, the patients in the present study had more disability than their matched population referents, but compared to a clinical spectre of peripheral nerve affections their disability levels at follow-up were relatively low.

We think that our results can be generalized to other populations of patients who are suspected of ulnar neuropathy. Although not validated, the prognostic model could be a useful tool for informing patients about the potential benefits of modifying occupational exposures and lifestyle factors. We found that the prognosis of the two patient groups differed with respect to disease-specific UNEQ scores, but not regarding general DASH scores. This corroborated our overall hypothesis that ulnar neuropathy confirmed by NCS differs from ulnar neuropathy-like symptoms with normal NCS, not only with respect to profile of risk factors $(16,17)$ but also with respect to prognosis.

In conclusion, distinction between ulnar neuropathy and ulnar neuropathy-like symptoms by means of NCS contained prognostic information with respect to severity of symptoms specific for ulnar neuropathy (as measured by UNEQ), but not with respect to degree of disability of the hands and arms (as measured by DASH). A negative impact of high occupational force requirements, current smoking, and obesity on both outcomes suggested that reduction of these factors might improve the prognosis of ulnar neuropathy and ulnar neuropathylike symptoms, but this remains to be shown.

\section{Acknowledgments}

The Danish Working Environment Research Fund funded the project (grant no. 13-2007-03 / 20070014773). We thank Johan Hviid Andersen, Jens Peder Lind Haahr, and Lone Donbæk Jensen, who provided expert ratings for the JEM, and data manager Michael Victor Christensen for his preparation of data from the Danish National Register on Public Transfer Payments for analysis.

\section{References}

1. Caliandro P, La TG, Padua R, Giannini F, Padua L. Treatment for ulnar neuropathy at the elbow. Cochrane Database Syst Rev. 2011;2:CD006839.

2. Roquelaure $\mathrm{Y}, \mathrm{Ha} \mathrm{C}$, Leclerc A, Touranchet A, Sauteron M, Melchior M, et al. Epidemiologic surveillance of upper-extremity musculoskeletal disorders in the working population. Arthritis Rheum. 2006;55(5):765-78. http:// dx.doi.org/10.1002/art.22222.

3. Latinovic R, Gulliford MC, Hughes RA. Incidence of common compressive neuropathies in primary care. J Neurol Neurosurg Psychiatry. 2006;77(2):263-5. http://dx.doi.org/10.1136/ jnnp.2005.066696.

4. Mondelli M, Giannini F, Ballerini M, Ginanneschi F, Martorelli E. Incidence of ulnar neuropathy at the elbow in the province of Siena (Italy). J Neurol Sci. 2005;234(1-2):5-10. http://dx.doi.org/10.1016/j.jns.2005.02.010.

5. Novak CB, Mackinnon SE, Stuebe AM. Patient self-reported outcome after ulnar nerve transposition. Ann Plast Surg. 2002;48(3):274-80. http://dx.doi.org/10.1097/00000637200203000-00008.

6. Svernlöv B, Larsson M, Rehn K, Adolfsson L. Conservative treatment of the cubital tunnel syndrome. J Hand Surg Eur Vol. 2009;34(2):201-7. http://dx.doi. org/10.1177/1753193408098480.

7. Beekman R, Wokke JH, Schoemaker MC, Lee ML, Visser LH. Ulnar neuropathy at the elbow: follow-up and prognostic factors determining outcome. Neurology. 2004;63(9):1675-80. http://dx.doi.org/10.1212/01.WNL.0000142535.24626.90.

8. Dunselman HH, Visser LH. The clinical, electrophysiological and prognostic heterogeneity of ulnar neuropathy at the elbow. J Neurol Neurosurg Psychiatry. 2008;79(12):1364-7. http:// dx.doi.org/10.1136/jnnp.2008.145110.

9. Friedrich JM, Robinson LR. Prognostic indicators from electrodiagnostic studies for ulnar neuropathy at the elbow. Muscle Nerve. 2011;43(4):596-600. http://dx.doi. org/10.1002/mus.21925.

10. Ohlsson K, Attewell RG, Johnsson B, Ahlm A, Skerfving S. An assessment of neck and upper extremity disorders by questionnaire and clinical examination. Ergonomics. 1994;37(5):891-7. http://dx.doi.org/10.1080/00140139408963698.

11. Sluiter JK, Rest KM, Frings-Dresen MH. Criteria document for evaluating the work-relatedness of upper-extremity musculoskeletal disorders. Scand J Work Environ Health. 2001;27 Suppl 1:1-102. http://dx.doi.org/10.5271/sjweh.637.

12. Midha R, Noble J, Patel V, Ho PH, Munro CA, Szalai JP. Prospective analysis of relationships of outcome measures for ulnar neuropathy at the elbow. Can J Neurol Sci. 2001;28(3):239-44.

13. Padua L, Aprile I, Caliandro P, Foschini M, Mazza S, Tonali P. Natural history of ulnar entrapment at elbow. Clin Neurophysiol. 2002;113(12):1980-4. http://dx.doi. org/10.1016/S1388-2457(02)00295-X. 
14. Juratli SM, Nayan M, Fulton-Kehoe D, Robinson LR, Franklin GM. A population-based study of ulnar neuropathy at the elbow in Washington State workers' compensation. Am J Ind Med. 2010;53(12):1242-51. http://dx.doi.org/10.1002/ajim.20866.

15. Novak CB, Anastakis DJ, Beaton DE, Mackinnon SE, Katz J. Biomedical and psychosocial factors associated with disability after peripheral nerve injury. J Bone Joint Surg Am. 2011;93(10):929-36. http://dx.doi.org/10.2106/ JBJS.J.00110.

16. Svendsen SW, Johnsen B, Fuglsang-Frederiksen A, Frost P. Ulnar neuropathy and ulnar neuropathy-like symptoms in relation to biomechanical exposures assessed by a job exposure matrix: a triple case-referent study. Occup Environ Med. 2012;69(11):773-80. http://dx.doi.org/10.1136/ oemed-2011-100499.

17. Frost P, Johnsen B, Fuglsang-Frederiksen A, Svendsen SW. Lifestyle risk factors for ulnar neuropathy and ulnar neuropathy-like symptoms. Muscle Nerve. In press 2013.

18. Beaton DE, Katz JN, Fossel AH, Wright JG, Tarasuk V, Bombardier C. Measuring the whole or the parts? Validity, reliability, and responsiveness of the Disabilities of the Arm, Shoulder and Hand outcome measure in different regions of the upper extremity. J Hand Ther. 2001;14(2):128-46. http:// dx.doi.org/10.1016/S0894-1130(01)80043-0.

19. Davis AM, Beaton DE, Hudak P, Amadio P, Bombardier C, Cole D, et al. Measuring disability of the upper extremity: a rationale supporting the use of a regional outcome measure. J Hand Ther. 1999;12(4):269-74. http://dx.doi.org/10.1016/ S0894-1130(99)80063-5.

20. Hudak PL, Amadio PC, Bombardier C. Development of an upper extremity outcome measure: the DASH (disabilities of the arm, shoulder and hand) [corrected]. The Upper Extremity Collaborative Group (UECG). Am J Ind Med. 1996;29(6):602-8. http://dx.doi.org/10.1002/(SICI)10970274(199606)29:6<602::AID-AJIM4>3.0.CO;2-L.

21. Fitzgerald BT, Dao KD, Shin AY. Functional outcomes in young, active duty, military personnel after submuscular ulnar nerve transposition. J Hand Surg Am. 2004;29(4):619-24. http://dx.doi.org/10.1016/j.jhsa.2004.04.011.

22. Novak CB, Anastakis DJ, Beaton DE, Katz J. Patientreported outcome after peripheral nerve injury. J Hand Surg Am. 2009;34(2):281-7. http://dx.doi.org/10.1016/j. jhsa.2008.11.017.

23. Zimmerman NB, Kaye MB, Wilgis EF, Zimmerman RM, Dubin NH. Are standardized patient self-reporting instruments applicable to the evaluation of ulnar neuropathy at the elbow? J Shoulder Elbow Surg. 2009;18(3):463-8. http://dx.doi. org/10.1016/j.jse.2009.02.010.

24. Mondelli M, Padua L, Giannini F, Bibbo G, Aprile I, Rossi S. A self-administered questionnaire of ulnar neuropathy at the elbow. Neurol Sci. 2006;27(6):402-11. http://dx.doi.org/10.1007/s10072-006-0719-3.

25. Lynge E, Sandegaard JL, Rebolj M. The Danish National Patient Register. Scand J Public Health. 2011;39(7 Suppl):30-3. http://dx.doi.org/10.1177/1403494811401482.
26. Andersen JS, Olivarius NF, Krasnik A. The Danish National Health Service Register. Scand J Public Health. 2011;39(7 Suppl):34-7. http://dx.doi.org/10.1177/1403494810394718.

27. Fuglsang-Frederiksen A, Pugdahl K. Current status on electrodiagnostic standards and guidelines in neuromuscular disorders. Clin Neurophysiol. 2011;122(3):440-55. http:// dx.doi.org/10.1016/j.clinph.2010.06.025.

28. Olney RK. Guidelines in electrodiagnostic medicine. Consensus criteria for the diagnosis of partial conduction block. Muscle Nerve Suppl. 1999;8:S225-S229.

29. Hjøllund NH, Larsen FB, Andersen JH. Register-based followup of social benefits and other transfer payments: accuracy and degree of completeness in a Danish interdepartmental administrative database compared with a population-based survey. Scand J Public Health. 2007;35(5):497-502. http:// dx.doi.org/10.1080/14034940701271882.

30. Svendsen SW, Frost P, Jensen LD. Time trends in surgery for non-traumatic shoulder disorders and postoperative risk of permanent work disability: a nationwide cohort study. Scand J Rheumatol. 2012;41(1):59-65. http://dx.doi.org/10.3109/0 3009742.2011 .595375 .

31. Jensen LD, Frost P, Schiøtz-Christensen B, Maribo PT, Christensen MV, Svendsen SW. Predictors of vocational prognosis after herniated lumbar disc - a two year follow up study of 2039 patients diagnosed at hospital. Spine (Phila Pa 1976) . 2011;36:E791-E797.

32. Müller U, Tänzler K, Bürger A, Staub L, Tamcan O, Roeder $\mathrm{C}$, et al. A pain assessment scale for population-based studies: Development and validation of the Pain Module of the Standard Evaluation Questionnaire. Pain. 2008;136(12):62-74. http://dx.doi.org/10.1016/j.pain.2007.06.014.

33. Franchignoni F, Giordano A, Sartorio F, Vercelli S, Pascariello B, Ferriero G. Suggestions for refinement of the Disabilities of the Arm, Shoulder and Hand Outcome Measure (DASH): a factor analysis and Rasch validation study. Arch Phys Med Rehabil. 2010;91(9):1370-7. http://dx.doi.org/10.1016/j. apmr.2010.06.022.

34. Padua R, Padua L, Ceccarelli E, Romanini E, Zanoli G, Amadio PC, et al. Italian version of the Disability of the Arm, Shoulder and Hand (DASH) questionnaire. Cross-cultural adaptation and validation. J Hand Surg Br. 2003;28(2):179-86. http://dx.doi.org/10.1016/S0266-7681(02)00303-0.

35. Royston P, Moons KG, Altman DG, Vergouwe Y. Prognosis and prognostic research: Developing a prognostic model. BMJ. 2009;338:b604.

36. Jester A, Harth A, Germann G. Measuring levels of upperextremity disability in employed adults using the DASH Questionnaire. J Hand Surg Am. 2005;30(5):1074. http:// dx.doi.org/10.1016/j.jhsa.2005.04.009.

37. Gummesson C, Atroshi I, Ekdahl C. The disabilities of the arm, shoulder and hand (DASH) outcome questionnaire: longitudinal construct validity and measuring self-rated health change after surgery. BMC Musculoskelet Disord. 2003;4:11. http://dx.doi.org/10.1186/1471-2474-4-11.

Received for publication: 29 October 2012 